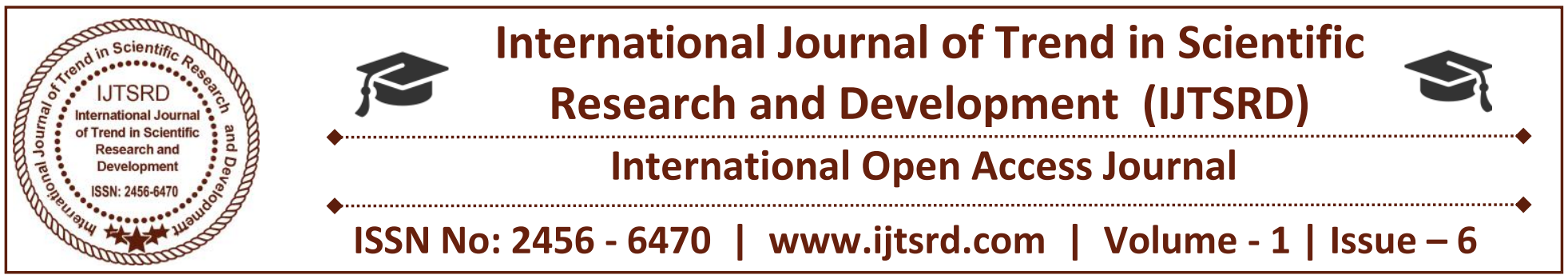

\title{
Improvement of Bioavailability of Valsartan through Novel Transdermal Drug Delivery System
}

\author{
Dr. Reena Antony \\ Assistant Professor \\ Department of Microbiology, \\ Career College, Bhopal, M.P., India
}

\section{ABSTRACT}

Valsartan is a potent and specific competitive angiotensin II antagonist which is used in the management of hypertension. It is well absorbed following oral administration, with rather poor bioavailability of about $25 \%$. Peak plasma concentration of valsartan occurs 2-4 hours after ingestion. Optimized VAL-SLN was prepared by preemulsion sonication method and sprays dried to improve the handling processing and stability. Solid state studies such as Infra Red Spectroscopy and Differential Scanning Calorimetry indicated absence of any chemical interaction between valsartan and the lipids. Prepared patches possess satisfactory physiochemical characteristics. The absorption of VAL-SLN patches (F-4) resulted in 2.02 fold increase in bioavailability as compared to oral capsule formulation. Results of pharmacokinetic studies indicated that the solid lipid nanoparticles can be successfully used as potential vehicles for enhancement of bioavailability of poorly soluble drugs. The aim of the study was to study the enhancement of bioavailability of valsartan from transdermally applied solid lipid nanoparticles.

Keywords: Valsartan, Transdermal, Nanoparticles, Drugs, Bioavailability

\section{INTRODUCTION}

Tablets and injections have been the traditional way to take medications; new options are becoming increasingly popular. One highly successful alternative delivery method is the transdermal route. This route may offer several benefits, including more consistent symptom control and enhanced convenience. The transdermal route has vied with oral treatment as the most successful innovative research area in drug delivery. In the USA (the most important clinical market), out of 129 drug delivery candidate products under clinical evaluation, 51 are transdermal or dermal systems; $30 \%$ of 77 candidate products in preclinical development represents such drug delivery. Few molecules that are under clinical development are listed in (Table 1) [1].

Table 1: Transdermal products that are in clinical development in the US

\begin{tabular}{|c|c|c|}
\hline COMPOUND & TDD TECHNOLOGY & $\begin{array}{l}\text { DEVELOPMENT } \\
\text { STAGE }\end{array}$ \\
\hline Alprostadil & Gel & Preclinical \\
\hline Buprenorphine & Patch & Phase III \\
\hline Dexamethasone & Iontophoresis & Phase III \\
\hline Dextroamphetamine & Patch & Preclinical \\
\hline
\end{tabular}


International Journal of Trend in Scientific Research and Development (IJTSRD) ISSN: 2456-6470

\begin{tabular}{|l|l|l|}
\hline Diclofenac & Patch & Preclinical \\
\hline Dihydrotestosterone & Gel & Phase III \\
\hline Estradiol & Gel & Phase III \\
\hline Androgen/Estradiol & Patch & Phase II \\
\hline Estradiol/Progestin & Patch & Submitted NDA \\
\hline Testosterone/Estradiol & Patch & Phase III \\
\hline Fentanyl & Patch, Iontophoresis & Preclinical to Phase III \\
\hline Flurbiprofen & Patch & Preclinical \\
\hline Lidocaine & Iontophoresis & Phase III \\
\hline Glucagon-like peptide-1 & Microneedle & Preclinical \\
\hline Methylphenidate & Patch & Submitted NDA \\
\hline Parathyroid hormone & Microneedle & Preclinical \\
\hline Rotigotine & Patch & Phase III \\
\hline Testosterone & Gel & Submitted NDA \\
\hline
\end{tabular}

Valsartan is a potent and specific competitive angiotensin II antagonist which is used in the management of hypertension. Valsartan is a novel and orally active Ang II antagonist that does not require hepatic metabolism. It is highly selective antagonist of Ang II at the AT1-receptor subtype and does not possess agonist properties. Valsartan is a safe and well tolerated antihypertensive agent in humans. Valsartan is well absorbed following oral administration, with rather poor bioavailability of about $25 \%$. Peak plasma concentration of valsartan occurs 2-4 hours after ingestion. Drug is not significantly metabolised and is excreted mainly via the bile as unchanged drug. Valsartan also has $\mathrm{pH}$ dependent solubility whereby, it ranges from very slightly soluble in an acidic environment to soluble in a neutral environment of the GI tract. Permeability of valsartan is low and also $\mathrm{pH}$ dependent where it decreases as environmental $\mathrm{pH}$ increases from acidic to a neutral $\mathrm{pH}$ values in GI tract. As a result of these complex biopharmaceutical properties, development of a more releasable and bioavailable dosage form of valsartan with less inter - and intra - subject variability is challenging [2].

\section{- Chemical structure of valsartan.}

Fig: 1

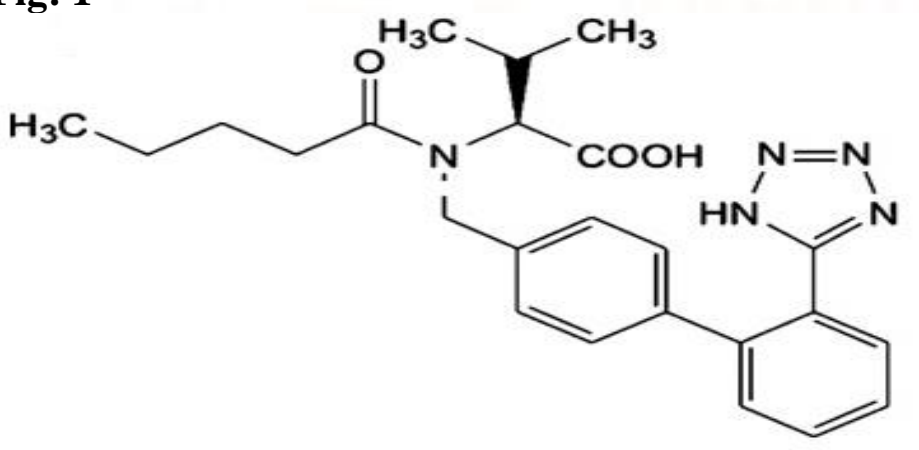

- Chemical formula: $\mathrm{C}_{24} \mathrm{H}_{29} \mathrm{~N}_{5} \mathrm{O}_{3}$

- Molecular weight: $435.52 \mathrm{~g} / \mathrm{mol}$

- Melting point: $105-110^{\circ} \mathrm{C}$

- Appearance: white microcrystalline powder

- Water solubility: Practically insoluble in water

Our skin is the largest organ of the human body with a surface area of approximately $1.5-2.0 \mathrm{~m}^{2}$ and an average thickness of $0.5 \mathrm{~mm}$ (ranging from $0.05 \mathrm{~mm}$ to $2 \mathrm{~mm}$ ). As interface between the body and the outside world is the skin which fulfils important protective as well as sensory functions. For the purpose of transdermal drug delivery, we can examine the structure and function of human skin categorized into four main layers.

1. The innermost subcutaneous fat layer (hypodermis)

2. The overlying dermis

3. The viable epidermis

4. The outermost layer of the tissue (a non-viable epidermal layer) the stratum 


\section{4) Fundamentals of skin permeations [3]}

In old days the skin was supposed to be impermeable with exception to gases. However, in the last century the study indicated the permeability to lipid soluble drugs. Also it was recognized that various layers of skin are not equally permeable i.e. epidermis is less permeable than dermis. The transdermal permeation can be visualized as composite of a series in sequence as:

1. Adsorption of a penetrant molecule onto the surface layers of stratum corneum.

2. Diffusion through stratum corneum and through viable epidermis.

3. Finally through the papillary dermis into the microcirculation.

\section{Materials and Equipment}

UV spectrophotometric method for analysis of valsartan was done by regular protocols and the values of absorbance were plotted graphically against

Table 2: General composition of pre-emulsion during initial studies

\begin{tabular}{|l|l|}
\hline Ingredient & Concentration (\%) \\
\hline Drug & 1 \\
\hline Compritol 888 ATO & $3-12$ \\
\hline Oil phase surfactant (Span 60,Soya lecithin) & $2-6$ \\
\hline Aqueous phase surfactant (Poloxamer 188, Tween 80) & $0.5-2$ \\
\hline Water & q s to $100 \mathrm{ml}$ \\
\hline
\end{tabular}

\section{Experimental design}

The traditional approach to developing a formulation is to change 1 variable at a time. By this method it is difficult to develop an optimized formulation, as the method reveals nothing about the interactions among the variables. Hence, a Box-Behnken statistical design with 3 factors, 3 levels, and 15 runs was selected for the optimization study. The experimental design consists of a set of points lying at the midpoint of each edge and the replicated centre point of the multidimensional cube [4]. Independent and dependent variables are listed in (Table 3). The polynomial equation generated is given below.

$\mathrm{Y}=\mathrm{K}+\mathrm{aX} 1+\mathrm{bX} 2+\mathrm{cX} 3+\mathrm{dX} 1 \mathrm{X} 2+\mathrm{e} \mathrm{X} 1 \mathrm{X} 3$

+ fX 2 X $3+$ g X $1 X 1+$ h X $2 X 2+i X 3$

$\mathrm{X} 3$....... methods. 2).

the concentration. For the preparation of solid lipid nanoparticles loaded with valsartan, drug should be completely soluble in lipid. Various lipids such as Compritol 888 ATO, Glyceryl Monostearate (GMS), Precirol ATO 5, Gelucire, Emulsire 61 and Stearic acid were used to study the solubility of drug. Solid Lipid Nanoparticles (SLN) can be prepared by various

\section{Pre-optimization studies for formulation of Pre- emulsion}

Pre-optimization studies of pre-emulsion were done with different concentration of Compritol 888 ATO to determine optimum percent of Compritol 888 ATO. Then, different surfactants with different concentration were used for initial optimization of pre-emulsion with optimum lipid concentration (Table 
Table 3: Variable and their levels in Box-Behnken design

\begin{tabular}{|l|l|l|l|}
\hline \multirow{2}{*}{$\begin{array}{l}\text { 1. Independent } \\
\text { variables }\end{array}$} & 2. Low & 3. Medium & 4. High \\
\hline 5. Drug:lipid & $6.1: 4$ & $7.1: 8$ & $8.1: 12$ \\
\hline 9. Span 60 & $10.2 \%$ & $11.4 \%$ & $12.6 \%$ \\
\hline $\begin{array}{l}\text { 13. Sonication } \\
\text { time(min) }\end{array}$ & 14.5 & 15.10 & 16.15 \\
\hline $\begin{array}{l}\text { 17. Transformed } \\
\text { values }\end{array}$ & $18 .-1$ & 19.0 & $20 .+1$ \\
\hline $\begin{array}{l}\text { 21. Dependent variables } \\
\text { 22. Y1= particle size } \\
\text { 23. Y2= entrapment efficiency }\end{array}$ & \\
\hline
\end{tabular}

\section{Preparation of Val-SLN dispersions}

Val-SLN was prepared by using pre-emulsion probe sonication method. The ingredients used and their levels taken for further study on formulation optimization of valsartan loaded SLN (VAL-SLN) dispersions (Table 4).

\section{Table 4: Composition of VAL-SLN dispersion for detailed studies}

\begin{tabular}{|l|l|}
\hline Ingredients & Composition (\%) \\
\hline Valsartan & 1 \\
\hline Compritol ATO 888 & $4-12$ \\
\hline Span 60 & $2-6$ \\
\hline Tween 80 & 2 \\
\hline Water & qs to $100 \mathrm{ml}$ \\
\hline
\end{tabular}

Optimization of preparation of Val-SLN was done by Design Expert Software (Version 7.1.6, Stat-Ease Inc. and Minneapolis, MN). Total five optimized formulations were selected as check points to validate Response Surface Methodology.

\section{Evaluation of VAL-SLN:}

Particle size distribution of freshly prepared and reconstituted spray dried SLNs dispersion in distilled water was measured by Particle Size Analyzer For determination of drug entrapment in SLNs, the drug loaded lipid nanoparticles were separated from free drug by Ultra-centrifugation. Solid state study were done by Drug content determination, FTIR study, DSC study etc

\section{Stability studies}

Stability studies on the optimized formulated patches (F-4) were carried out as per ICH guidelines. Drug content were used to check the stability of the formulation after predetermined time. Samples were withdrawn at the end of 0,30,60 and 90 days and evaluated for Drug content.

\section{RESULTS}

\section{Selection of lipid}

Selection of lipid was done on the basis of maximum solubility of valsartan in different lipids and also on melting point of lipid as the type of drug-lipid matrix and drug release pattern will depend on it. Out of different lipids used, valsartan showed maximum solubility in Compritol ATO 888 (Fig. 2) 


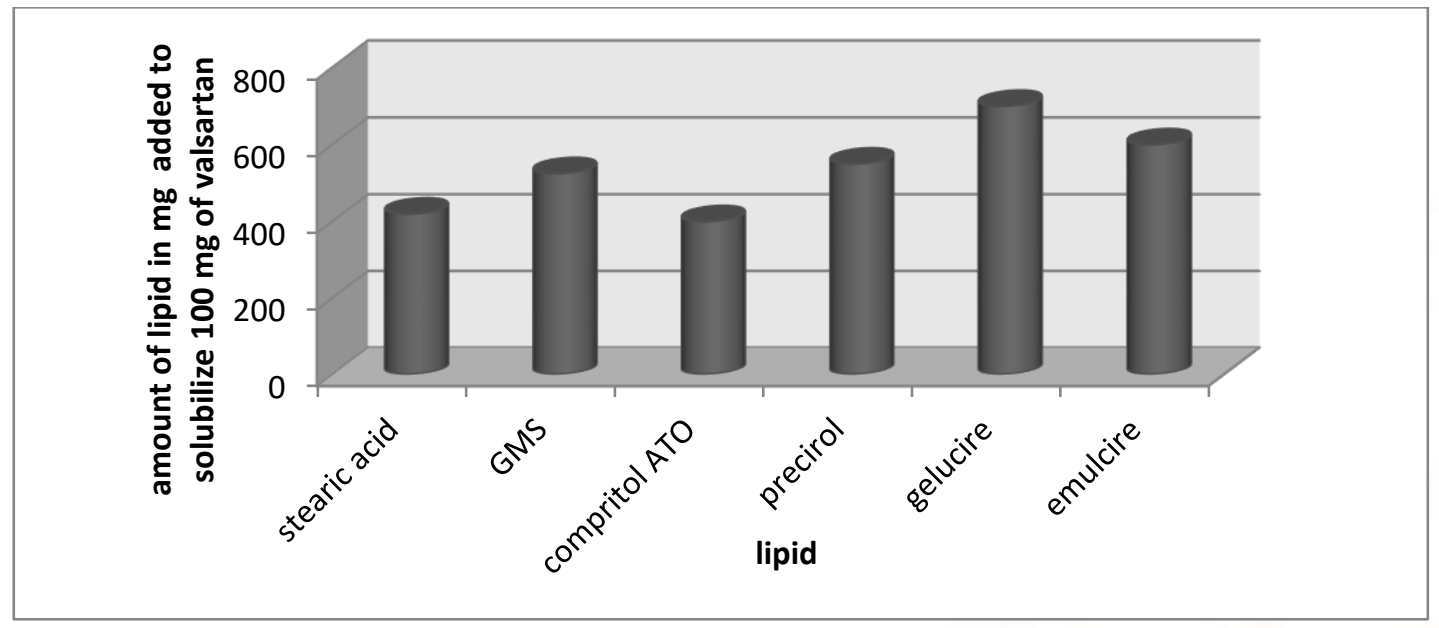

Fig.2: Solubility of valsartan in different lipids

\section{Evaluation of VAL-SLN:}

\section{Particle size determination}

The particle size analysis of the nanoparticulate dispersion by laser diffraction using Malvern
Mastersizer showed particle size in the range between 149.3nm to $473 \mathrm{~nm}$. Particle size distribution curve of optimized sample $\mathrm{O}_{4}$ was $224.32 \mathrm{~nm}$ is shown below (Fig.3).

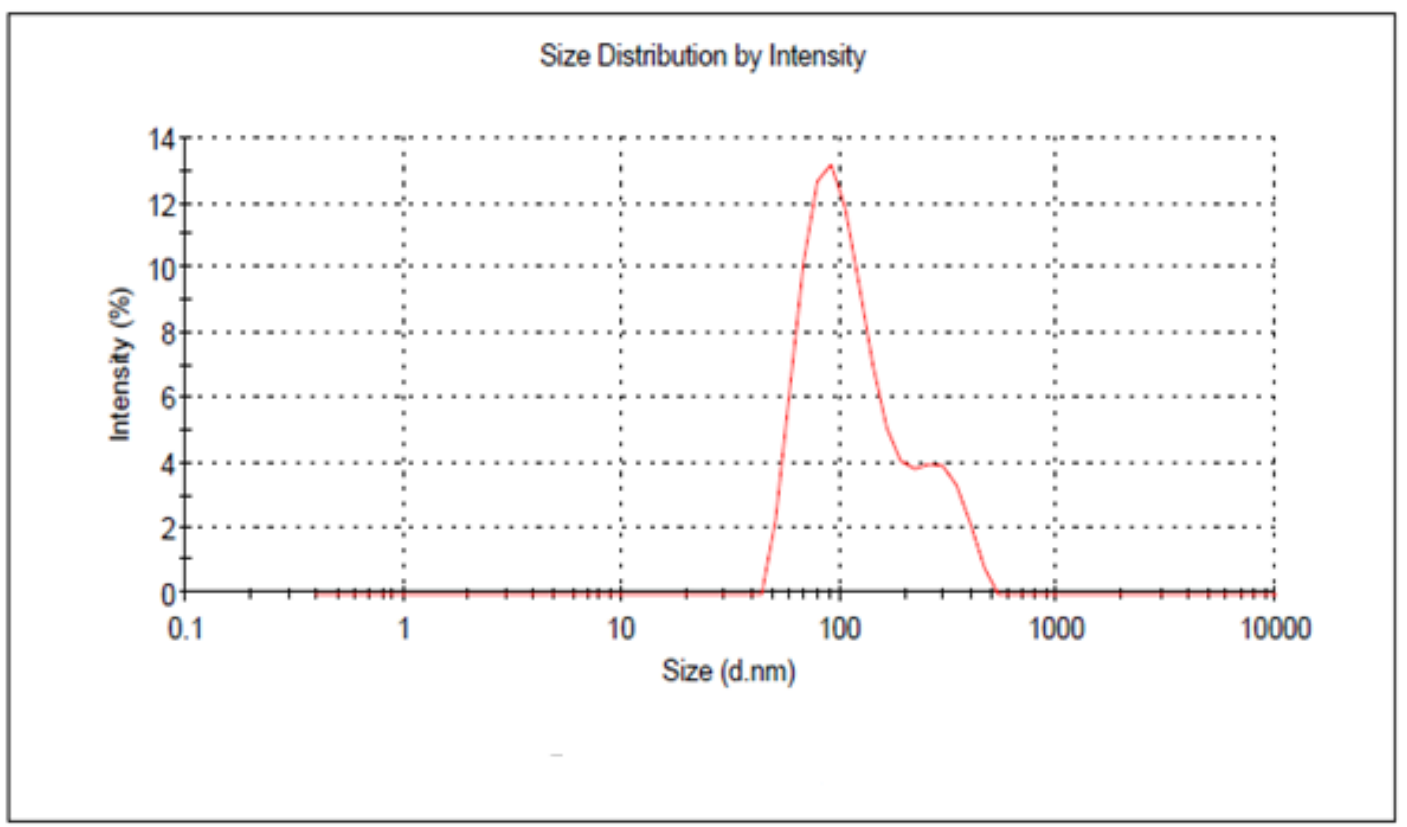

Fig. 3: Particle size distribution curve of Sample $\mathrm{O}_{4}$

\section{Solid state study}

\section{Drug content determination}

Drug content of optimized formulations were shown in following (Table 5)

\section{Table 5: Drug content of optimized formulation}

\begin{tabular}{|l|c|}
\hline Formulation & Drug content (\%) \\
\hline O-1 & $97.34 \pm 0.8$ \\
\hline O-2 & $98.12 \pm 1.2$ \\
\hline O-3 & $98.76 \pm 0.5$ \\
\hline O-4 & $99.01 \pm 0.2$ \\
\hline
\end{tabular}

Data shows mean $(n=3) \pm S D$

\section{FTIR study}

From FTIR study, the characteristic peak of drug such as ketonic $\mathrm{C}=\mathrm{O}$ stretch $\left(1602 \mathrm{~cm}^{-1}\right)$, acid $\mathrm{C}=\mathrm{O}$ stretch $\left(1726 \mathrm{~cm}^{-1}\right)$, carboxylic group (-COOH stretch) 3000$3300 \mathrm{~cm}^{-1}$, aromatic and aliphatic (C-H stretch) 2900$3000 \mathrm{~cm}^{-1}$ disappeared and were replaced by the peak of Compritol 888 ATO as shown in (Fig. 4) This established drug entrapment in lipid matrix. 


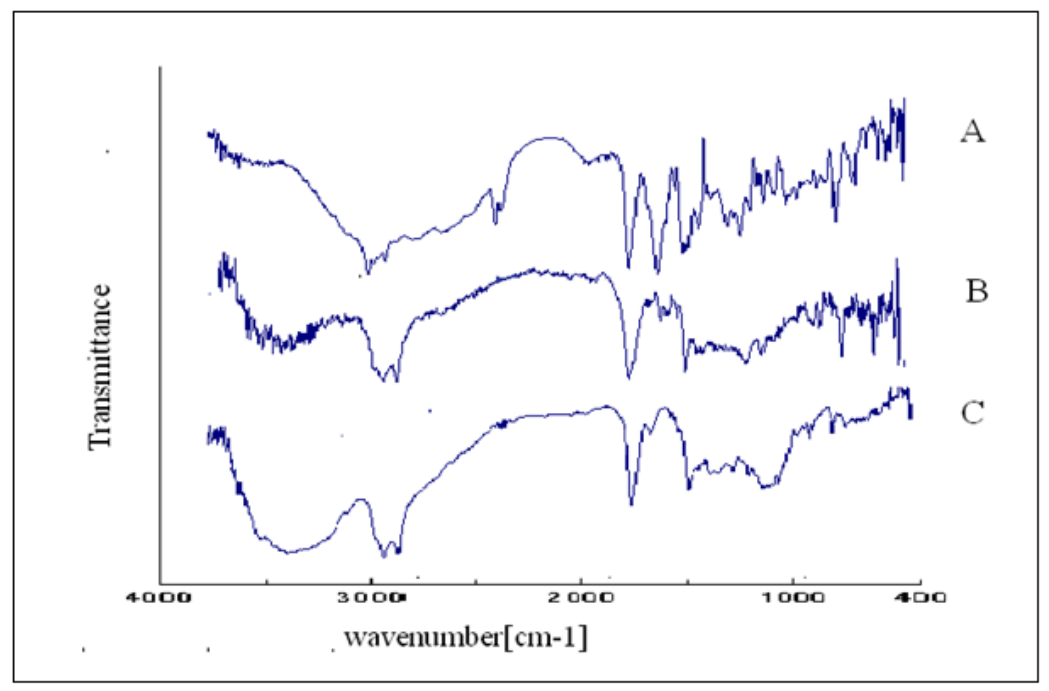

Fig. 4: FTIR spectra of valsartan (A); compritol ATO 888 bulk (B); VAL-SLN(C).

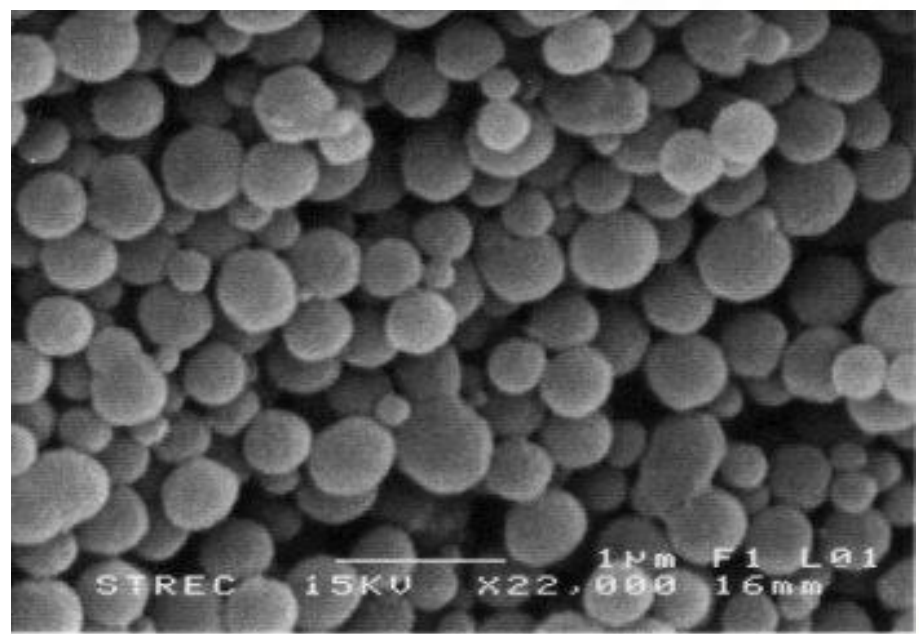

Fig. 5: SEM of valsartan loaded solid lipid nanoparticles

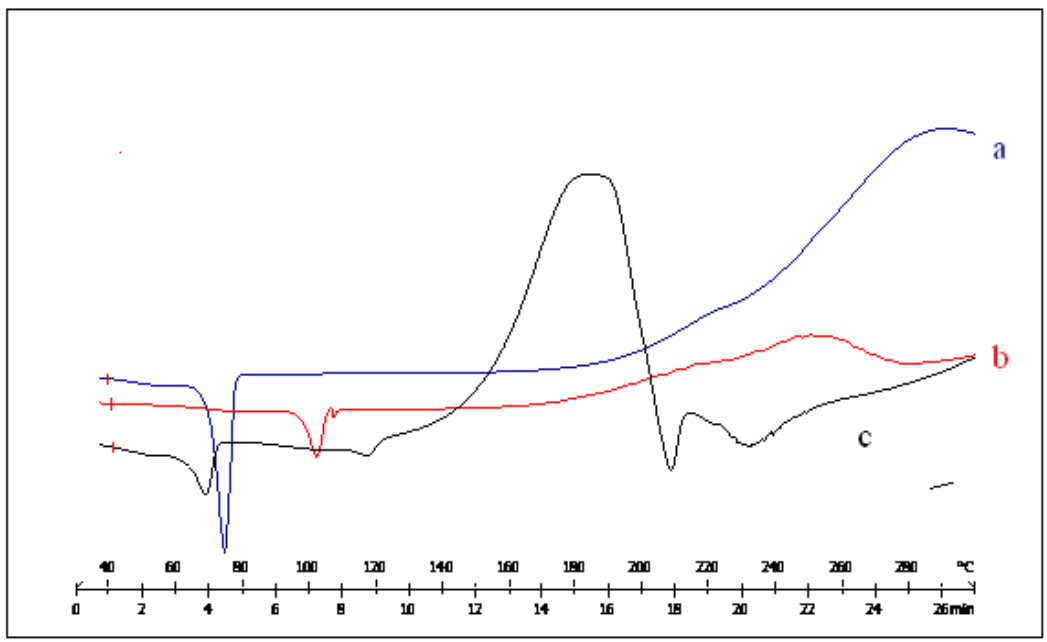

Fig. 5: DSC thermograms of bulk compritol ATO 888 (a); pure valsartan (b); VAL-SLN (c) 
Table 6: Drug content during stability studies

Data shows mean $(n=3) \pm$ SD

\begin{tabular}{|c|c|}
\hline Storage time & $\%$ drug content \\
\hline One month & $95.12 \pm 0.21$ \\
\hline Two month & $94.92 \pm 0.14$ \\
\hline Three month & $95.3 \pm 0.23$ \\
\hline
\end{tabular}

\section{CONCLUSION}

Optimized VAL-SLN was prepared by pre-emulsion sonication method and sprays dried to improve the handling processing and stability. Transdermal patches incorporating valsartan loaded solid lipid nanoparticles (VAL-SLN) and plain valsartan were prepared by solvent evaporation method using polymer matrix containing ethyl cellulose (EC) and polyvinyl pyrrolidone (PVP) in different ratio, of which PVP:EC (3:2) was selected as relatively best ratio compare to other with respect to drug release study and used for further study. Prepared patches possess satisfactory physiochemical characteristics.
Results of pharmacokinetic studies indicated that the solid lipid nanoparticles can be successfully used as potential vehicles for enhancement of bioavailability of poorly soluble drugs.

\section{REFERENCES}

[1] Beverley J. T., Barrie C. F., The transdermal revolution, Drug Discovery Today, 9 (16), (2004), 697-703.

[2] Tripathi K.D., Essentials of medical pharmacology, Jaypee brothers, medical publisher, Delhi, (2004), 321-322.

[3] Bronaugh R., Maibach H., Percutaneous Absorption Drug-Cosmetics-MechanismMethodology, $3^{\text {rd }}$ ed., Marcel Dekker, 101-102.

[4] 45Solanki A. B., Parikh J. R., Formulation and optimization of piroxicam proniosomes by 3factor, 3-level Box-Behnken design, AAPS PharmSciTech. 2007; 8(4): Article 86. 